\title{
Measuring relative efficiency of applied science and technology universities in province of Semnan, Iran and providing suggestions for merging units
}

\author{
Abolfazl Danaei ${ }^{\mathrm{a}}$ and Shamsi Aliabadi ${ }^{\mathrm{b}^{*}}$
}

${ }^{a}$ Department of management, Semnan branch, Islamic Azad University, Semnan, Iran

${ }^{b}$ Department of Industrial management, Semnan branch, Islamic Azad University, Semnan, Iran

\section{H R O N I C L E}

\section{Article history:}

Received October 1, 2012

Received in revised format

5 February 2012

Accepted 7 February 2013

Available online

February 142013

Keywords:

Components of Accounting

Information Quality

Accreditation of Loans

Bank Contracts \begin{abstract}
A B S T R A C T
University of applied science and technology has been designed to create a platform for multilateral activities such as industrial, military and academic in developing countries to promote science and scientific research applications. These universities are responsible to promote practical training in quantitative and qualitative indicators and they provide appropriate infrastructure to implement theoretical graduates to solve practical problems to build necessary infrastructure to transfer modern technology into developing countries. During the past few years, there have been tremendous development on these units but some of them have not been efficient. In this paper, we present an empirical study to measure the relative efficiencies of various units of applied science and technology universities using data envelopment analysis. The proposed model of this paper uses two inputs including human resources as well as total assets and two outputs including the number of graduate students as well as operating profit. The results of the study have indicated that some of the units are inefficient and need to be merged with other units to increase the relative efficiency of these universities.
\end{abstract}

\section{Introduction}

University of applied science and technology has been designed to create a platform for multilateral activities such as industrial, military and academic in developing countries to promote science and scientific research applications. These universities are responsible to promote practical training in quantitative and qualitative indicators. These universities provide appropriate infrastructure to implement theoretical graduates in solving practical problems to build necessary infrastructure to transfer modern technology into developing countries. Measuring the relative efficiency of universities has been a major concern among professionals and there have been various methods used to measure the performance of similar non-for-profit organizations such as universities (Charnes et 
al., 1978; Charnes et al., 1994). A standard data envelopment analysis normally yields more than one efficient unit and there is a need to use supper efficiency for measuring the relative efficiency of efficient ones (Anderson \& Peterson, 1993). There are some studies on supper efficiency of various organizations obtained from the implentation of data envelopment analysis. Avkiran (2010), for instance, investigated the relationship between the supper-efficiency estimations and some major important financial ratios for some Chinese banking sector.

Ahmadkhani and Babakhani (2011), for instance, presented a study on measuring relative efficiencies of test drive educational organizations using data envelopment analysis. They implemented a Delphi method to detect the most important input/output factors and then gathered the actual data for all training units located in province of Zanjan, Iran. Azizi and Paktinat (2011) measured the relative efficiency of 11 private universities located in region ten of Islamic Azad university in Iran. They assigned some points for human resources including university professor and regular employees and considered it along with assets as inputs of DEA model. The survey provided found the inefficient units where there was a low correlation between the supper-efficiency and desirable financial ratios.

Staub et al. (2010) performed a comprehensive study on different factors influencing the relative efficiency of Brazilian banks including related expenditures and technical efficiencies over the period 2000-2007. Hemati and Mehdiabadi (2011) used an integrated data envelopment analysis with Malmquist index to measure the relative efficiency and productivity of different units of an Iranian bank. Data envelopment analysis has also been used for other industrial applications including layout planning (Bozorgi \& Abedzadeh, 2011; Fallah et al., 2011). Zaheri et al. (2012) implemented multiple criteria decision making models for ranking customers of bank network based on loyalty properties in weighted RFM model. The applicaion was also involved with the implementation of data envelopment analysis. Hemmati et al. (2011) measured the relative efficiency of some banks and compared the results with TOPSIS, which is another multi criteria decision making method.

Lin et al. (2009) applied various data envelopment methods for measuring the relative efficiency of 117 branches of a certain bank in Taiwan and stated an overall technical efficiency of 54.8\% among them. Yang et al. (2010) did another investigation on measuring the relative efficiency of banks based on hybrid minimax reference point and data envelopment analysis.

In this paper, we perform an investigation to measure the relative efficiency of various applied science and technology universities in province of Semnan, Iran. The organization of the paper first investigate the propsoed method in section 2. The results are discussed in section 3 and concluding remarks are given in the last to summarize the contribution of the paper.

\section{The proposed model}

The proposed investigation of this paper uses data envelopment analysis (DEA) to measuring the relative performance of all applied science and technology universities in province of Semnan, Iran.

As we have already explained, Charnes, et al. $(1978,1994)$ are the first who introduced the idea of constant return to scale DEA (CCR) for measuring the relative efficiency of decision making units (DMU). It is an straightforward task to demonstrate that DMU works whenever a production function is available. However, there are various cases where providing an analytical form for this function cannot be possible. Therefore, we use a set of production feasibility, which incorporates some principles such as fixed-scale efficiency, convexity and feasibility as follows,

$T_{C}=\left\{(X, Y) \mid X \geq \sum_{j=1}^{n} \lambda_{j} X_{j}, Y \leq \sum_{j=1}^{n} \lambda_{j} Y_{j}, \lambda_{j} \geq 0, j=1, \cdots n\right\}$, 
where $X$ and $Y$ are input and output vectors, respectively. The CCR production feasibility set border describes the relative efficiency in which any off-border DMU is assumed as inefficient point. The CCR framework is determined in two types of either input or output oriented. The input CCR concentrates on decreasing the maximum input level with a ratio of $\theta$ so that, at least, the same output is generated, i.e.:

$\min \theta$

subject to

$\theta X_{p}-\sum_{j=1}^{n} \lambda_{j} X_{i j} \geq 0$,

$\sum_{j=1}^{n} \lambda_{j} Y_{r j} \geq Y_{r p}$,

$\sum_{j=1}^{n} \lambda_{j}=1$,

$\lambda_{j} \geq 0, \quad j=1, \cdots, n$.

Model (2) represents an input orientated CCR form of DEA where $\theta$ is the relative efficiency of the DMU and we can observe that the optimal value of $\theta, \theta^{*}$, is a number between zero and one and once the dual of model (2) is demonstrated we have,

$\min \sum_{r=1}^{s} u_{r} y_{r 0}+u_{0}$

subject to

$\sum_{i=1}^{m} v_{i} X_{i 0}=1$,

$\sum_{i=1}^{m} v_{i} X_{i 0}-{ }_{i p} \sum_{i=1}^{m} v_{i} X_{i j}+u_{0} \leq 0, \quad j=1, \cdots, n$.

$u_{r} \geq 0, \quad r=1, \cdots, s$.

$v_{i} \geq 0, \quad i=1, \cdots, m$

In the event we study the dual fuzzy two-phase BCC form, the first phase is as follows,

$\max : \phi$

subject to

$$
\begin{array}{ll}
\sum_{j=1}^{n} \mu_{j} x_{i j} \leq x_{i 0} \quad, \quad i=1, \ldots, m \\
\sum_{j=1}^{n} \mu_{j} y_{r j} \geq \phi y_{r 0} \quad, \quad r=1, \ldots, s \\
\sum_{j=1}^{n} \mu_{j}=1 & , j=1, \ldots, n \\
\mu_{j} \geq 0 & , j=1, \ldots, n
\end{array}
$$

$\phi$ free.

Besides, the second phase of fuzzy BCC is as follows, 
$\max : \quad w=\sum_{i=1}^{m} S_{i}^{-}+\sum_{r=1}^{s} S_{r}^{+}$

subject to

$$
\begin{aligned}
& \sum_{j=1}^{n} \mu_{j} x_{i j}+S_{i}^{-}=x_{i 0}, \quad i=1, \ldots, m \\
& \sum_{j=1}^{n} \mu_{j} y_{r j}-S_{r}^{+}=\phi^{*} y_{r 0}, \quad r=1, \ldots, s \\
& \sum_{j=1}^{n} \mu_{j}=1, \quad j=1, \ldots, n \\
& \mu_{j} \geq 0, \quad j=1, \ldots, n \quad S_{i}^{-} \geq 0, \quad i=1, \ldots, m \quad S_{r}^{+} \geq 0, r=1, \ldots, s .
\end{aligned}
$$

The two-stage DEA methods has been popular technique for measuring the relative efficiency of different financial and non-finacial units (Khaki et al., 2011). Jalili Sabet, and Fadavi (2011), for instance, used measured relative efficiencies of insurance firms using a two-stage DEA method. Ahadian et al. (2011) used a combination of DEA with GAHP for supplier selection. Hemati et al. (2011) performed an empirical study to measure the relative efficiency and strategic planning using BSC-DEA and DEMATEL.

\section{The results}

In this section, we report the results of the implementation of DEA method to measure the relative efficiency of various units. The proposed study of this paper assigns some points for human resources including university professor and regular employees and takes into account it along with assets as inputs of DEA model. Table 1 shows inputs/outputs of the proposed model.

\section{Table 1}

Inputs/outputs of the proposed model

\begin{tabular}{lccccc}
\hline & \multicolumn{3}{c}{ Inputs } & \multicolumn{3}{c}{ Outputs } \\
\cline { 2 - 7 } Unit & Assets & Human resource points & Graduated students & Operating profit & Efficiency(Rank) \\
\hline 1 & $1,000,000,000$ & 48 & 284 & $647,771,600$ & $1(1)$ \\
2 & $1,078,922,840$ & 89 & 455 & $3,255,168,120$ & $1(1)$ \\
3 & $2,068,208,680$ & 137 & 709 & $5,243,270,270$ & $1(1)$ \\
4 & $650,000,000$ & 40 & 0 & $198,000,000$ & $1(1)$ \\
5 & $130,000,000,000$ & 158 & 254 & $220,000,000$ & $0.36(11)$ \\
6 & $161,900,000$ & 51 & 228 & $487,350,000$ & $1(1)$ \\
7 & $15,000,000,000$ & 40 & 250 & $121,260,000$ & $1(1)$ \\
8 & $982,500,000$ & 229 & 310 & $607,000,000$ & $0.53(10)$ \\
9 & $212,238,000$ & 74 & 81 & $-309,671,400$ & $0.30(12)$ \\
10 & $942,380,000$ & 104 & 250 & $532,100,000$ & $0.56(9)$ \\
11 & $145,000,000$ & 240 & 490 & $760,750,000$ & $1(1)$ \\
12 & $200,000,000$ & 66 & 87 & $375,050,000$ & $0.60(8)$ \\
\hline
\end{tabular}

As we can observe from the results of Table 1, there are 7 units out of 12 ones, which are reported efficient. The lowest efficiency unit belongs to unit 9 with relative efficiency of 0.30 followed by unit 5 and units 8 and 10 maintain average efficiencies of 0.53 and 0.56 , respectively. The average efficiency is 0.78 , which means there is a $22 \%$ gap among these units. Therefore, we need to perform a merge between some units to reduce the existing gaps. The proposed study proposes to combine unit 3 and unit 8 and calls a new dummy unit, A where the inputs are calculated by summing up assets and human resource point to 3,050,708,680 and 366, respectively. In addition, we consider the outputs of the new generated unit are calculated as summing up the graduated students and operating profits of 1019 and 5,850,270,270, respectively. Note that the operating profit would be even higher in real-world since the fixed cost will be reduced, significantly as a result of restructuring the new 
unit. Similarly we build a new unit, B, by merging units 4 and 12 together and build a new unit $\mathrm{C}$ by integrating units 2 and 5.

The results of the implementation of DEA indicate that all old units remain efficient except unit 9 and unit 10 with relative efficiencies of 0.30 and 0.65 , respectively. In addition, the relative efficiencies of units A, B and C are 1, 0.39 and 0.95 , respectively brining us to an average efficiencies of 0.81 . This means the gap could be reduced to 0.19 from 0.22 and there could be some improvement on relative efficiencies of inefficient units. However, we need to be careful about the newly built unit B, which is still inefficient. We may conclude that a serious restructure on inputs of this particular unit would be necessary.

\section{Conclusion}

In this paper, we have presented an empirical study to measure the relative efficiencies of 12 Applied Science universities in province of Semnan, Iran. The study has considered total assets and human resources as inputs and operating profit as well as number of graduated students as output and using DEA technique has measured the relative efficiencies of these units. The study has concluded that some of these units were inefficient and proposed building three dummy units by merging some of the inefficient units. The results of implementation of DEA technique have revealed that there would be some improvement on average efficiency of units.

\section{References}

Ahadian, B., Gholipour, A., \& Abadi, M., \& Motamed Chaboki, R. (2011). A new DEA-GAHP method for supplier selection problem. Management Science Letters, 2(7), 2485-2492.

Ahmadkhani, A., \& Babakhani, M. (2011). An empirical study to measure the relative efficiencies of training organizations using data envelopment analysis. Management Science Letters, 1(2), 195202.

Avkiran, N. K. (2010). Association of DEA super-efficiency estimates with financial ratios: Investingating the case for Chinese banks. Omega, 39(3), 323-334.

Anderson, P., \& Peterson, N. C. (1993). A procedure for ranking efficient units in data envelopment analysis. Management Science, 39(10), 1261-1264.

Azizi, Z., \& Paktinat, M. (2011). A DEA application for analyzing investment activities in higher educational organizations. Management Science Letters, 3(2), 435-442.

Bozorgi, N., \& Abedzadeh, M. (2011). A multiple criteria facility layout problem using data envelopment analysis. Management Science Letters, 1(3), 363-370.

Cook, W. D., \& Kress, M. (1990). A data envelopment model for aggregating preference rankings. Management Science, 36, 1302-1310.

Charnes A, Cooper, W. W., Rhodes, E. (1978). Measuring the efficiency of decision making units. European Journal of the Operational Research, 2, 429-44.

Charnes A, Cooper W. W., Lewin, A., Seiford, L. M. (1994). Data envelopment analysis: theory, methodology and applications. Massachusetts: Kluwer Academic Publishers.

Chen, S. J., \& Hwang, C. L. (1992). Fuzzy multiple attribute decision making: Methods and applications. Berlin: Springer-Verlag.

Fallah, M., Aryanezhadb, M.B., Najafi, S.E., \& Shahsavaripour, N. (2011). An empirical study on measuring the relative efficiency using DEA method: A case study of bank industry. Management Science Letters, 1(1), 49-56.

Hemati, M., \& Mehdiabadi, A. (2011). An empirical study to measure the relative efficiency and productivity of different units of an Iranian bank using DEA and Malmquist index. Management Science Letters, 1(3), 307-314.

Hemmati, M., Dalghandi, S.A., \& Nazari, H. (2011). Measuring relative performance of banking industry using a DEA and TOPSIS. Management Science Letters, 3(2), 499-504. 
Hemati, M., Danaei, A., \& Shahhosseini, M. (2011). An empirical study to measure the relative efficiency and strategic planning using BSC-DEA and DEMATEL. Management Science Letters, 2(4), 1109-1121.

Jalili Sabet, R., \& Fadavi, A. (2011). Performance measurement of insurance firms using a two-stage DEA method. Management Science Letters, 3(1), 303-308.

Khaki, A.R., Najafi, S.E., \& Rashidi, S. (2011). Improving efficiency of decision making units through BSC-DEA technique. Management Science Letters, 2(1), 245-252.

Staub, R. B., Da Silva e Souza, G. \& Tabak, B. M. (2010). Evolution of bank efficiency in Brazil: A DEA approach. European Journal of Operational Research, 202(1), 204-213.

Yang, J.B., Wong, B.Y.H., Xu, D.L., Liu, X.B. \& Steuer, R.E. (2010). Integrated bank performance assessment and management planning using hybrid minimax reference point - DEA approach. European Journal of Operational Research, 207(3), 1506-1518.

Zaheri, F., Farughi, H., Soltanpanah, H., Alaniazar, S., \& Naseri, F. (2012). Using multiple criteria decision making models for ranking customers of bank network based on loyalty properties in weighted RFM model. Management Science Letters, 2(1), 697-704. 